\title{
Heat Shock Protein 27 Immune Complex Altered Signaling and Transport (ICAST): Novel Mechanisms of Attenuating Inflammation
}

Chunhua Shi PhD, Jingti Deng MD, PhD, Michael Chiu MD, MSc, Yong-Xiang Chen MD, PhD, Edward R. O'Brien, MD

Libin Cardiovascular Institute of Alberta, Calgary, Alberta, Canada

Running title: HSP27 ICAST

\section{Address for correspondence:}

Edward R. O'Brien, MD, FRCPC, FAHA, FACC, FESC

Professor, Division of Cardiology, Department of Cardiac Sciences,

Libin Cardiovascular Institute of Alberta

Health Research \& Innovation Centre, Rm GC68

3280 Hospital Drive NW, Calgary, Alberta,

Canada T2N 4Z6

Tel. 403-220-4525

Fax 403-210-9739

e-mail: ermobrie@ucalgary.ca 


\section{Nonstandard Abbreviations}

$\mathrm{AAb}$ - anti-HSP27 (or anti-HSP25) antibodies

$\mathrm{ApoE}^{-/-}$- apolipoprotein E null

a.u. - absorbance units

BSA - bovine serum albumin

HSP -heat shock protein

HSP27 - Heat Shock Protein 27

IL-10 - interleukin-10

IL-1 $\beta$ - interleukin-1 beta

LDL - low density lipoprotein cholesterol

LDLR - low density lipoprotein receptor

$\mathrm{NF}-\kappa \mathrm{B}$ - nuclear factor kappa light chain enhancer of activated B cells

ON - overnight

oxLDL - oxidized LDL

PBS - phosphate buffered saline

PBST - PBS tween

rC1 - recombinant C-terminal truncation of HSP27 spanning amino acids 90-205

rHSP27 - recombinant HSP27

Strep-HRT - streptavidin-horse radish peroxidase

TLR-4 - toll-like receptor 4

TMB - 3,3',5,5'-tetramethylbenzidine 
HSP27 ICAST
Abstract
Blood levels of heat shock protein (HSP27) and natural IgG auto-antibodies to HSP27 (AAbs) are higher in healthy controls compared to cardiovascular disease patients. Vaccination of mice with recombinant HSP25 (rHSP25, murine ortholog of human rHSP27) increased AAb levels, attenuated atherogenesis and reduced plaque inflammation and cholesterol content. We sought to determine if the HSP27 immune complex (IC) altered MФ inflammation signaling (Toll Like Receptor 4; TLR4), and scavenger receptors involved in cholesterol uptake (SR-AI, CD-36). Combining a validated polyclonal IgG anti-HSP27 antibody (PAb) with rHSP27 enhanced binding to THP-1 MФ cell membranes and activation of NF- $\kappa \mathrm{B}$ signaling via TLR4, competing away LPS and effecting an anti-inflammatory cytokine profile. Similarly, adding the PAb with rHSP27 enhanced binding to SR-AI and CD-36, as well as lowered oxLDL binding in HEK293 cells separately transfected with SR-AI and CD-36, or THP-1 MФ. Finally, the PAb enhanced the uptake and internalization of rHSP27 in THP-1 MФ. Thus, the HSP27 IC potentiates HSP27 cell membrane signaling with receptors involved in modulating inflammation and cholesterol uptake, as well as HSP27 internalization. Going forward, we will explore HSP27 Immune Complex Altered Signaling and Transport (ICAST) as a new anti-inflammatory therapeutic strategy in vivo. 
HSP27 ICAST

\section{Introduction}

Atherosclerosis is a chronic inflammatory disease of the artery wall that is characterized by the accumulation of lipids in macrophages (MФ) (1). Heat Shock Protein 27 (HSP27) is a member of the small heat-shock protein family that is primarily known as an intracellular chaperone, and more recently for its extracellular, anti-inflammatory roles (2). Our laboratory demonstrated that HSP27 is a potential biomarker for atherosclerosis, with its expression attenuated in the presence of atherosclerosis (3) - an observation that 4 other groups confirmed using objective (proteomic discovery) approaches (4-7). In humans, low serum HSP27 levels are associated with the presence of coronary artery disease and a higher 5-year likelihood of future adverse clinical events (e.g., heart attack, stroke, cardiovascular death) (8). Cross-breeding mice that overexpress HSP27 with atherosclerosis-prone $A p o E^{-/-}$mice we demonstrated that HSP27 reduces serum and plaque cholesterol levels, vessel wall inflammation and unstable lesion formation (810). In vitro, recombinant HSP27 reduced MФ uptake of modified low density lipoprotein (LDL), inhibited secretion of the pro-inflammatory cytokine interleukin-1 $\beta$ (IL-1 $\beta)$ and promoted the release of anti-inflammatory IL-10 (9). Moreover, HSP27 binds to scavenger receptor AI (SR-AI) thereby reducing lipid uptake and the conversion of MФ into foam cells (9).

Recently, we discovered that blood levels of natural IgG (but not IgM) auto-antibodies to HSP27 (AAbs) are higher in healthy control subjects compared to cardiovascular disease patients (11). Vaccinating ApoE $^{-/-}$mice with recombinant HSP25 (rHSP25; murine ortholog of human rHSP27) increased AAb levels, attenuated atherogenesis, reduced plasma cholesterol levels as well as the abundance of plaque inflammation and cholesterol content. As the role of these AAbs in athero-protection is not yet clear, we began our studies by trying to determine how the 


\section{HSP27 ICAST}

immune complex (IC) that forms between HSP27 and AAbs alters: i) MФ signaling, looking specifically at the NF- $\kappa \mathrm{B}$ inflammation pathway, and ii) the uptake of oxidized LDL (oxLDL). We used a validated rabbit anti-HSP27 polyclonal antibody (PAb) that shares the same epitope mapping pattern as human plasma derived AAbs (11). Herein, we show that compared to HSP27 alone, the HSP27 IC shows enhanced cell membrane interactions that result in altered signaling with key receptors involved in inflammation (Toll Like Receptor 4; TLR4) and oxLDL uptake via the scavenger receptors, SR-AI and CD-36.

\section{Methods and Materials}

\section{Cell Culture Experiments}

a) The THP-1 monocytic M $\Phi$ cell line was obtained from American Type Culture Collection (ATCC\# TIB-202; Manassas, VA) and incubated at $37^{\circ} \mathrm{C}$ and $5 \% \mathrm{CO}_{2}$ in complete RPMI 1640 growth medium supplemented with $10 \mathrm{U} / \mathrm{ml}$ penicillin and streptomycin, $1 \mathrm{mM}$ sodium pyruvate (11965092; Thermo Fisher Scientific, Burlington, ON) and heat inactivated 10\% Fetal Bovine Serum (FBS; Gibco, Burlington, ON). These undifferentiated mononuclear cells (between passage 3 and 16) were seeded in 24 -well plates at concentration of $1 \times 10^{6}$ cells / well, and stimulated with $50 \mathrm{ng} / \mathrm{ml}$ phorbol 12-myristate 13-acetate (PMA; Sigma-Aldrich, Oakville, ON) to induce differentiation to MФ-like cells (12).

b) HEK-Blue ${ }^{\text {TM }}$ Null1-v and HEK-Blue ${ }^{\text {TM }}$-TLR4 (stably expressing TLR4, MD-2 and CD14 coreceptor genes) cell lines were obtained from Invivogen (SanDiego, CA, USA). HEK-Blue ${ }^{\mathrm{TM}}$ SR-AI and HEK-Blue ${ }^{\mathrm{TM}}$ CD36 were prepared by stably transfecting the parental cell line HEK-Blue ${ }^{\mathrm{TM}}$ Null1-v with plasmid pCMV/Hygro-SR-AI or pCMV/Hygro-CD36 (Sino Biological Inc., North Wales, PA) and selecting using the addition of $100 \mu \mathrm{g} / \mathrm{mL}$ hygromycin. 
HSP27 ICAST

The medium for all the HEK-Blue ${ }^{\mathrm{TM}}$ cell lines was DMEM, supplemented with $4.5 \mathrm{~g} / \mathrm{l}$ glucose, 2-4 mM L-glutamine with heat-inactivated 10\% (v/v) FBS, $50 \mathrm{U} / \mathrm{ml}$ penicillin, and $50 \mu \mathrm{g} / \mathrm{ml}$ streptomycin. All HEK-Blue ${ }^{\mathrm{TM}}$ cell lines contain an inducible secreted embryonic alkaline phosphatase (SEAP) reporter gene under the control of an IFN- $\beta$ minimal promoter fused to five NF- $\kappa \mathrm{B}$ and AP-1-binding sites (Invivogen).

c) THP1 XBlue ${ }^{\mathrm{TM}}$ cells (Invivogen) that were maintained and subcultured in complete RPMI1640 media supplemented with Zeocin $(200 \mu \mathrm{g} / \mathrm{mL})$ as a selective antibiotic.

\section{Recombinant Protein preparation}

Plasmids encoding HIS-tagged full-length recombinant HSP27 (rHSP27) or the C-terminal, biologically inactive (rC1) fragment of HSP27 (AA93-205) (Supplemental Fig. 1A) were constructed using a pET-21a vector, and the plasmids were transformed into an Escherichia coli expression strain (DE3) as described previously (13). Recombinant proteins were purified with a Ni-NTA resin and Q-Sepharose ${ }^{\mathrm{TM}}$ (GE Healthcare, Mississauga, ON). Endotoxin was removed using the Pierce ${ }^{\mathrm{TM}}$ High-Capacity Endotoxin Removal Resin (ThermoFisher Scientific; Burlington, ON). The purity of the final recombinant proteins was more than $99 \%$ with an endotoxin concentration lower than 2 units/mg protein by Limulus Amebocyte Lysate PYROGENT $^{\mathrm{TM}} 125$ Plus (Lonza; Walkersville, MD).

\section{Generation and Validation of Anti-HSP27 IgG polyclonal antibody}

A rabbit polyclonal IgG antibody (PAb) mimicking the human HSP27 autoantibody was produced according to the standard procedure by Cedarlane Laboratories (Burlington, ON) and the standard requirements of the Canadian Council on Animal Care. The production and 
HSP27 ICAST

validation of this PAb is previously described (11). To verify the fidelity of this PAb we compared its immunoreactivity with a commercial (goat) anti-HSP27 antibody using Western blotting of rHSP27 and rHSP25. As well, we used a spot blot epitope mapping technique to compare the immunoreactivity of the PAb vs. naturally occurring anti-HSP27 antibodies found in human plasma. Specific 15-mers of the linearized protein reacted with the PAb in a pattern that was identical to that of the naturally occurring AAbs - whether they were derived from the blood of healthy control or cardiovascular disease subjects. The binding of the PAb to these epitopes was abrogated by the addition of rHSP27 $(100 \mu \mathrm{g} / \mathrm{ml} v s$. an irrelevant anti-human IgG negative control), thereby indicating that epitopes in the full-length rHSP27 were similar to those on the spot blot.

\section{Fast Protein Liquid Chromatography (FPLC)}

The molecular size of the $\mathrm{rHSP} 27$ and $\mathrm{rC} 1$ proteins with or without the PAb (using ratios of 1:1 and 1:5 for Hsp27:PAb; wt:wt) was determined by size exclusion chromatography in AKTA Primer Plus fast protein liquid chromatography system (GE Healthcare) with Superose ${ }^{\mathrm{TM}} 6$ 10/30 GL Column (GE Healthcare; Supplemental Fig. 1B). Samples were diluted in phosphate buffered saline (PBS) to $20 \mu \mathrm{g} / \mathrm{ml}$ and the PAb was mixed with rHSP27 for $30 \mathrm{mins}$. A final sample volume of $0.2 \mathrm{ml}$ was loaded on the columns, the fractions were eluted with $0.2 \mathrm{ml} / \mathrm{min}$ PBS buffer and absorption was monitored at $280 \mathrm{~nm}$. A standard curve was constructed using a mix of blue dextran (2,000 kD, Millipore Sigma, Oakville, ON), apoferritin (443 kD, Millipore Sigma,), Alcohol Dehydrogenase from yeast (150 kD; Millipore Sigma) and bovine serum albumin (BSA; 66kD), as well as human LDL and HDL (Biomedical Technologies). 
HSP27 ICAST

\section{Physical Interaction Between HSP27 and PAb}

Isothermal Titration Calorimetry (ITC) was used to gauge the strength of the interaction between HSP27 and the PAb, as reflected by the energy released from the interaction of two components (14-17). ITC experiments were performed using an ITC200 micro-calorimeter (MicroCal, North Hampton MA USA) with a reaction cell and reference cell volume of $200 \mu \mathrm{L}$ and a syringe volume of $40 \mu \mathrm{L}$. PAb and rHSP27 were prepared in PBS (pH 7.4) with dialysing membranes utilized to remove impurities. All solutions were degassed for $20 \mathrm{mins}$ at $37^{\circ} \mathrm{C}$ prior to loading into the cells or syringe. The ligand was titrated into the reaction cell in $2 \mu \mathrm{L}$ aliquots for a duration of 4 secs with 160 secs intervals in between additions. A total of 20 injections per experiment were used, with the first injection volume of $0.2 \mu \mathrm{L}$ for 0.4 secs to remove any extraneous bubbles from the syringe. In order to account for the heat of dilution, PAb was also titrated into PBS and subtracted from the data set. MicroCal Origin 7 software (https://www.originlab.com) was utilized to perform data analysis and fitment of titration curves to a one binding site model (Supplemental Fig. 1C).

\section{Membrane Binding Assay}

To determine the affinity of HSP27 to bind the cell membrane with or without the PAb, THP-1 MФ were incubated with biotin-labeled rHSP27 or rC1 plus streptavidin-horse radish peroxidase (strep-HRP) at $4^{\circ} \mathrm{C}$ for 30 mins to prevent endocytosis of the reagents. Cells were then washed thrice with cold PBS. The substrate 3,3',5,5'-tetramethylbenzidine (TMB; Millipore Sigma) was then added to detect the retained HRP activity for 10 mins. The reaction was stopped by $2 \mathrm{~N}$ $\mathrm{H}_{2} \mathrm{SO}_{4}$ and the color was quantified at $450 \mathrm{~nm}$ using a Synergy Mx plate reader (BioTek; Winooski, VT). 
HSP27 ICAST

\section{$[$ rHSP27 + PAb] Binds TLR4}

Previously, we showed that HSP27 (alone) binds TLR4, and activates the NF- $\kappa$ B pathway in a TLR4 dependent manner (18). We now sought to determine if addition of the PAb enhances the binding of rHSP27 to TLR4 (see schematic overview: Supplemental Fig. 2A). First, we set up a system to pull down the TLR4 protein. An anti-TLR4 capture antibody (100 ng/well in carbonate-bicarbonate buffer; R\&D Systems, Minneapolis, MN) with demonstrable specificity for TLR in vitro (see Western blot: Supplemental Fig. 2B) was coated onto NUNC maxisorp plates covered with an adhesive plastic and incubated overnight at $4^{\circ} \mathrm{C}$. The coating solution was then removed, and the plate was blocked by adding $200 \mu 1 \%$ BSA in phosphate buffered saline tween (PBST) per well for at least 2 hrs at room temperature (RT). Next, we harvested TLR4 from THP-1 MФ as follows. Approximately $5 \times 10^{7} \mathrm{THP}-1 \mathrm{M} \Phi$ were re-suspended in $1 \mathrm{ml}$ of $2 \%$ Trition-100/PBST, vigorously shaken for at least $2 \mathrm{hrs}$ at $4^{\circ} \mathrm{C}$, followed by the addition of $4 \mathrm{ml}$ $1 \%$ BSA/PBS before being homogenized by sonication for 10 secs. After washing twice with $200 \mu \mathrm{l}$ PBST, $100 \mu \mathrm{l}$ of THP-1 MФ lysate was added to the plate for an additional $1 \mathrm{hr}$ incubation at RT to pull down TLR4. Finally, $100 \mu$ of PBST containing $1 \%$ BSA with $1 \mu \mathrm{g} / \mathrm{ml}$ biotinylated $\mathrm{rC} 1$ or $\mathrm{rHSP} 27$ in the presence or absence of $5 \mu \mathrm{g} / \mathrm{ml} \mathrm{PAb}$ and $1 \mu \mathrm{g} / \mathrm{ml}$ strep-HRP was then applied for the interaction assay. After a $1 \mathrm{hr}$ incubation at RT, the plate was washed 3 times with $200 \mu \mathrm{l} /$ well, mixed with $100 \mu \mathrm{l}$ of TMB and incubated for 10 mins at RT for development of the blue color. The reaction was stopped by the addition of $50 \mu \mathrm{l} 2 \mathrm{M} \mathrm{H}_{2} \mathrm{SO}_{4}$ and the optical absorbance at $450 \mathrm{~nm}$ was read using a Synergy Mx plate reader (Fig. 1B). 
HSP27 ICAST

\section{[rHSP27 + PAb] Activates NF-אB via TLR4}

To test the impact of the HSP27 IC on inflammatory signaling we conducted two experiments, both involving cells containing an NF- $\mathrm{KB}$ reporter construct. These experiments were done with the previously reported knowledge that the amount of endotoxin contamination in these recombinant proteins is measurably low, and of no functional consequences - as the addition of polymyxin B did not alter the NF- $\mathrm{KB}$ signal $(12,13)$. Lipopolysaccharide (LPS; from E. coli O111:B4, Cedarlane;) the principal component of Gram-negative bacteria that activates the innate immune system via TLR4, was used as a comparative positive control for both experiments.

The first experiment (Fig. 1C) sought to confirm the specificity and requirement for signaling of TLR4 in NF- $\kappa B$ signaling; hence, we used Human Embryonic Kidney (HEK) Blue ${ }^{\mathrm{TM}}$ Null1-v (i.e., devoid of TLR4) and HEK Blue ${ }^{\mathrm{TM}}$ TLR4 (stably expressing TLR4, MD-2 and CD14 coreceptor genes) cell lines (Invivogen). Cells were subject to treatment for 24 hrs with rHSP27 (1 $\mu \mathrm{g} / \mathrm{mL}), \mathrm{rC} 1(1 \mu \mathrm{g} / \mathrm{mL}), \mathrm{PAb}(5 \mu \mathrm{g} / \mathrm{mL}), \mathrm{rHSP} 27(1 \mu \mathrm{g} / \mathrm{mL})$ or rC1 $(1 \mu \mathrm{g} / \mathrm{mL})$ plus PAb (5 $\mu \mathrm{g} / \mathrm{mL}$ ) or LPS (10 ng/mL). The conditioned media from each treatment group was analyzed for the presence of SEAP using QUANTIBlue ${ }^{\mathrm{TM}}$ detection reagent (Invivogen) according to the manufacturer's instructions. Briefly, QUANTI-Blue ${ }^{\mathrm{TM}}$ detection reagent was mixed with cell supernatant $(10: 1)$ and incubated at $37^{\circ} \mathrm{C}$ for up to $1 \mathrm{hr}$. Optical absorbance at $620 \mathrm{~nm}$ was then measured using the BioTek Synergy Mx microplate reader. Media only controls (no cells) were assayed to ensure that there was no endogenous SEAP activity in the treatment media. 


\section{HSP27 ICAST}

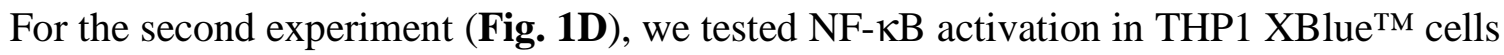

(Invivogen) treated with PBS as a control, and various combinations of rHSP27, PAb, and two concentrations of LPS (10 and $100 \mathrm{ng} / \mathrm{ml})$, before assaying the conditioned media for SEAP.

\section{LPS Competitive Binding Assay}

To compare the avidity of HSP27 with or without the PAb in competing with TLR4 we established an LPS competitive binding assay. After pulling down TLR4, $10 \mathrm{ng} / \mathrm{ml}$ of biotinylated LPS (LPS-EB from E. coli O111:B4; Cedarlane) was mixed with rHSP27 (concentration varying from 0 to $10 \mu \mathrm{g} / \mathrm{ml})$ in the presence or absence of PAb $(5 \mu \mathrm{g} / \mathrm{ml})$ plus strep-HRP (1ug/ml). The binding of biotinylated LPS to TLR4 was then quantified using a Synergy Mx plate reader (BioTek) to record optical absorbance at $450 \mathrm{~nm}$.

\section{Cytokines assays}

For 2 hrs, THP-1 MФ were treated with LPS (10 ng/ml) plus rHSP27 or rC1 $(1 \mu \mathrm{g} / \mathrm{ml})$ with or without PAb $(5 \mu \mathrm{g} / \mathrm{ml})$. PBS or PAb alone constituted additional control treatments. The culture media was then harvested and the concentrations of human IL-1 $\beta$ and IL10 were measured using ELISAs (DY201 and DY217B, R\&D Systems, Oakville, ON).

\section{[rHSP27 + PAb] Binds Scavenger Receptors}

Previously, we showed that HSP27 (alone) binds SR-AI (9) and we now sought to determine if the HSP27 IC also binds SR-AI as well as the closely related scavenger receptor CD-36. SR-AI and CD-36 proteins were pulled down from MФ membrane extracts as described above for TLR4 using anti-SR-A (R\&D System, 1:1000) and anti-CD36 (R\&D System, 1:1000) antibodies with 
HSP27 ICAST

demonstrable affinities (see Western blots: Supplemental Fig. 2B). Next, PBST (100 $\mu$ l)

containing $1 \% \mathrm{BSA}, 1 \mu \mathrm{g} / \mathrm{ml}$ biotinylated $\mathrm{rC} 1$ or $\mathrm{rHSP} 27$ in the presence or absence of $5 \mu \mathrm{g} / \mathrm{ml}$

$\mathrm{PAb}$ and $1 \mu \mathrm{g} / \mathrm{ml}$ strep-HRP were added to determine if there was an interaction between the HSP27 IC and the pulled-down scavenger receptors, as reflected by quantification of HRP activity as described for the TLR4 binding assay (Fig. 2A, 2B).

\section{Competitive Binding Assays for Scavenger Receptors}

Competitive inhibition assays were devised to compare the binding of oxLDL to either SR-AI or CD-36 in the presence of either rHSP27 or [rHSP27 + PAb]. As described for the TLR4 competitive binding assay described above, SR-AI and CD36 were separately pulled down from M $\Phi$ cell lysates, and the binding of biotinylated oxLDL to these receptors was measured while the concentration of rHSP27 was varied (0 to $2.7 \mu \mathrm{g} / \mathrm{ml}$ ) in the presence or absence of PAb (Fig. 2C, 2D). The opposite competition assay (Fig. 2E, 2F) was also devised, looking at the binding of biotinylated rHSP27 (with or without PAb) to either SR-AI or CD-36 while the concentration of oxLDL was varied $(0-164 \mu \mathrm{g} / \mathrm{ml})$. Strep-HRP $(1 \mathrm{ug} / \mathrm{ml})$ was then applied to create a quantifiable colorimetric reaction product reflective of the degree of interaction with either scavenger receptor.

\section{MФ Flow Cytometry Assay for DiI-oxLDL Uptake}

Uptake of oxLDL was analyzed using the following cells and assays:

i) To test the hypothesis that PAb also potentiates HSP27-mediated oxLDL uptake via scavenger receptors, HEK-Blue SR-AI and HEK-Blue CD36 cells were prepared from the parent cell line (HEK-Blue ${ }^{\mathrm{TM}}$ Null1-v) by stable transfection plasmid pCMV/Hygro-SR-AI or 


\section{HSP27 ICAST}

pCMV/Hygro-CD36 (Sino Biological Inc.) using Hygromycin as the selective antibiotic. The HEK-Blue cell lines were grown in DMEM, 4.5 g/l glucose, 2-4 mM L-glutamine with 10\% FBS (heat activated), penicillin, streptomycin and Normocin ${ }^{\mathrm{TM}}$ (Invivogen). To confirm the expression of the transiently transfected scavenger receptors Western blotting and FACS were used, with the results summarized in Supplemental Fig. 3A - 3D. All cells were grown to $80 \%$ confluence, then treated with $\mathrm{rHSP} 27$ or $\mathrm{rC} 1$ with or without PAb (or PAb alone as a control) and incubated with $1 \mu \mathrm{g} / \mathrm{ml}$ Dil-oxLDL for $2 \mathrm{~h}$. Cells were washed in PBS twice, detached and subsequently washed in $1 \times$ PBS and analyzed by flow cytometry with the phycoerythrin (PE) channel on $532 \mathrm{~nm}$ using a BD LSRII flow cytometer (BD Biosciences, San Jose, CA). The results are summarized (Fig. 3A) using data from one of three representative experiments, each quantifying: a) the percentage of cells that were fluorescent, and b) the mean fluorescence intensity (MFI) which represents the amount of DiI-oxLDL uptake for a particular experimental condition.

ii) Similarly, FACS was used to assess oxLDL uptake in THP-1 MФ incubated with $1 \mu \mathrm{g} / \mathrm{ml}$ rHSP27 or $\mathrm{rC} 1$ conjugated with FITC in the presence or absence of $5 \mu \mathrm{g} / \mathrm{ml} \mathrm{PAb}$ (as well as PAb alone) for 16 hours. MФ were then washed twice in PBS, detached using $1 \times$ trypsinEDTA, washed in $1 \times$ PBS and the FITC signal was analyzed at $488 \mathrm{~nm}$ on a BD LSRII flow cytometer (Fig. 3B).

iii)Finally, using a plate reader assay, THP-1 MФ (1 M/ml) grown to 80\% confluence in 96 well plates and incubated for 2 hours with $1 \mu \mathrm{g} / \mathrm{ml}$ DiI-oxLDL plus rHSP27 or rC1 with or without PAb, or the PAb alone. Plates were washed thrice with $200 \mu \mathrm{l}$ DPBS, and the density of DiloxLDL was read using a BioTek Synergy Mx microplate reader at $570 \mathrm{~nm}$ (Fig. 3C). 
HSP27 ICAST

\section{Assessment of rHSP27 Uptake by M $\Phi$}

Similar to the experiments described above, the uptake of FITC-labelled rHSP27 with or without PAb was assessed in MФ using both FACs and phase contrast / fluorescent confocal microscopy (Fluoview FV10i Confocal Microscope; Olympus, Center Valley, PA) (Fig. 4A 4C).

\section{Statistical analysis}

Unless stated otherwise, all data sets are represented as means \pm standard error of the mean of experiments performed at least 3 times. Statistical significance was assessed by using a one-way ANOVA (Graph Pad Prism 8, La Jolla,CA, USA), and Tukey's comparison of the groups. A pvalue $<0.05$ was considered significant.

\section{Results}

\section{Characterization of the HSP27-AAb complex}

A previously described rabbit polyclonal IgG anti-HSP27 antibody (PAb) with immunoreactivity similar to that of a commercial (goat) anti-HSP27 antibody and an epitope mapping pattern comparable to that of AAbs found in human serum was used for these studies (11). To characterize the size of the ICs formed with the addition of the PAb, rHSP27 and rC1 were incubated with PAb and the molecular sizes of the resulting ICs were determined by gel filtration analysis using FPLC (Supplemental Fig. 1B). The HSP27 IC is large (>30,000kDa) compared to rHSP27 alone $(100-500 \mathrm{kDa})$ or the PAb alone $(\sim 200 \mathrm{kDa})$. Increasing the rHSP27:PAb ratio from 1:1 to 1:5 led to a further increase in the IC size. The interaction between the PAb and rHSP27 was assessed using isothermal titration calorimetry and found to be an exothermic 
HSP27 ICAST

reaction $\left(\Delta \mathrm{H}=-3.0 \times 10^{-4} \mathrm{cal} / \mathrm{mol}\right)$ with a Ka of $8.9 \times 10^{-4} \mathrm{M}^{-1}$ with an average $\mathrm{N}$ valve of $0.5-$ consistent with a 2:1 binding ratio for PAb:HSP27 (Supplemental Fig. 1C).

\section{Binding of the HSP27 Immune Complex to MФ Cell Membrane}

Recently, we showed that the HSP27 IC can alter gene expression (11).Hence, we now begin to explore its interaction with the cell membrane and signaling. While rHSP27 bound to the MФ cell membrane with greater affinity than control treatments (BSA or rC1 without or with PAb), the PAb augmented rHSP27 cell surface binding $271 \%$ compared to $\mathrm{rHSP} 27$ alone $(\mathrm{p}<0.0001$; Fig. 1A).

Given that exogenous HSP27 therapy attenuates the early inflammatory stages of atherogenesis $(8,10,12)$, and that more recently this anti-inflammatory effect is amplified with rHSP25 vaccination (11), we sought explore the interaction between the HSP27 IC with TLR4. TLR4 protein was pulled down from the membrane fraction of THP-1 MФ and verified using a monoclonal anti-TLR4 antibody confirmed to be specific to TLR4 (Supplemental Fig. 2B). Binding of biotinylated rHSP27 or $\mathrm{rC} 1$ (in the presence or absence of PAb) to TLR4 was assessed using strep-HRP activity to reflect the interaction intensity. The PAb promoted the interaction between rHSP27 and the TLR4 complex by 104\% more than rHSP27 alone (Fig. 1B). $\mathrm{rC} 1$ alone or samples without either the anti-TLR4 antibody or the MФ membrane protein fraction containing TLR4 showed only background noise signals. Interestingly, the interaction between $[\mathrm{rC} 1+\mathrm{PAb}]$ and TLR4 was comparable to that of rHSP27 (alone) and TLR4 - perhaps indicating that it is the HSP27 alpha-crystallin domain (found in the $\mathrm{rC} 1$ fragment) that is important for the interaction with TLR4. The PAb did not interact with TLR4 complex, thus 
HSP27 ICAST

implying that the increased interaction with TLR4 in the presence of PAb was not from the PAb per se, but from the [rHSP27 + PAb] IC. Of note, the interaction with TLR4 increased by $125 \%$ as the ratio of HSP27 to PAb was increased from 1:1 to 1:5 (Supplemental Fig. 2C).

\section{PAb potentiates HSP27 NF- $\mathrm{KB}$ signaling in THP-1 MФ}

Previously, we show that rHSP27 activates NF- $\kappa$ B signaling in THP-1 MФ and characterized the downstream transcriptional events. It is important to note that in these experiments we noted altered expression of both pro- and anti-inflammatory genes $(12,13)$. To determine if the binding of the HSP27 IC to TLR4 altered NF- $\mathrm{KB}$ signaling, we employed a SEAP reporter gene assay in HEK293 cells stably expressing TLR4 and its co-receptors, MD-2 and CD14 (i.e., HEK Blue ${ }^{\text {TM }}$ TLR4 cells). HEK Blue ${ }^{\mathrm{TM}}$ parental cells deficient of TLR4 were used as a control (i.e., HEK Blue $^{\mathrm{TM}}$ Null cells) and essentially showed no response to any treatment (Fig. 1C). In contrast to rHSP27 alone, the combination of [rHSP27 + PAb] showed $68 \%$ more NF- $\kappa$ B activation. LPS alone showed an NF- $\mathrm{KB}$ activation signal that was $122 \%$ greater than the HSP27 IC. Hence, TLR4 is required for HSP27 activation of the NF- $\mathrm{KB}$ pathway in these HEK Blue ${ }^{\mathrm{TM}}$ cells but, compared to LPS, was quite modest. It is important to note that both $\mathrm{rC} 1$ and $\mathrm{rHSP} 27$ are generated in bacteria - so if there was significant endotoxin contamination that might activate the $\mathrm{NF}-\kappa \mathrm{B}$ pathway it should be reflected by both of these treatments and therefore balance out. Moreover, we previously showed that adding polymyxin B to neutralize the effect of any potential endotoxin contaminants of the recombinant proteins made no difference in the NF- $\mathrm{KB}$ signal $(12,13)$. 
HSP27 ICAST

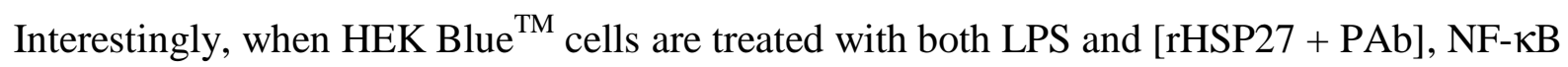
activation is moderately attenuated. For example, while treatment with LPS 10 and $100 \mathrm{ng} / \mathrm{ml}$ increased NF- $\kappa \mathrm{B}$ activity by almost 4- and 6-fold; respectively. In the presence of the HSP27 IC the LPS-induced increase in NF- $\mathrm{KB}$ activity was reduced $26 \%$ and $46 \%$; respectively $(\mathrm{p}<0.0001$; Fig. 1D). The same concentrations of $\mathrm{rC} 1, \mathrm{rHSP} 27$ alone, $\mathrm{PAb}$ or $[\mathrm{rC} 1+\mathrm{PAb}]$ showed neither inhibition nor promotion of NF- $\mathrm{KB}$ signaling compared to PBS control. Hence, these data suggest a competitive relationship between the HSP27 IC and LPS for the TLR4 receptor complex.

To further address this competition between LPS and the HSP27 IC, we set up a competitive binding assay for TLR4 pulled down from the membrane fraction of THP-1 MФ. Compared to rHSP27 alone, [rHSP27 + PAb] reduced LPS binding to TLR4 by 77\% (p<0.0001; Fig. 1E). Finally, we assessed the downstream effects of these binding experiments by looking at THP-1

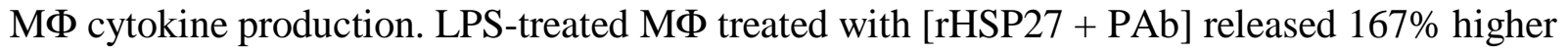
levels of the anti-inflammatory cytokine IL-10 and 75\% lower levels of the pro-inflammatory cytokine IL-1 $\beta$ compared to PBS control ( $p<0.001$; Fig. 1F).

\section{The HSP27 Immune Complex interacts with MФ Scavenger Receptors}

Previously, we showed that rHSP27 (alone) binds SR-AI to reduce modified LDL uptake (9) and now assess if the addition of the PAb to rHSP27 alters oxLDL binding to SR-AI or its related scavenger receptor, CD-36. MФ membrane extracts or SR-AI and CD-36 were pulled down and their identities were verified by Western blotting (Supplemental Fig. 2B). Compared to rHSP27 alone the PAb promoted the interaction between rHSP27 and SR-AI, as well as rHSP27 and CD- 


\section{HSP27 ICAST}

$36(\mathrm{p}<0.01$ and $\mathrm{p}<0.001$ respectively; Fig. 2A, 2B). $\mathrm{rC} 1$ alone, $\mathrm{PAb}$ alone or samples without either the anti-SR-AI or anti-CD-36 antibodies, or the MФ membrane protein fraction containing either SR-AI or CD-36 showed only background noise signals. Interestingly, the interaction between $[\mathrm{rC} 1+\mathrm{PAb}]$ and CD-36 was comparable to that of rHSP27 (alone) - perhaps indicating that it is the HSP27 alpha-crystallin domain (also found in the $\mathrm{rC} 1$ fragment) that is important for the interaction with CD-36. Of note, as the ratio of HSP27 to anti-HSP27 antibody is increased from 1:1 to 1:5, using excess PAb, the interaction with SR-AI and CD-36 increased by approximately 2.5- and 1.5-fold; respectively (Supplemental Fig. 2D, 2E).

\section{HSP27 Immune complex competes with oxLDL for SR-AI and CD36 binding}

As both scavenger receptors are involved in $\mathrm{M} \Phi$ lipoprotein uptake we next assessed whether the HSP27 IC can compete for oxLDL binding to SR-AI or CD-36 pulled down from M $\Phi$ cell lysates. [rHSP27 + PAb] was superior to rHSP27 alone in competing with oxLDL for binding to SR-AI or CD36, with less than $0.5 \mu \mathrm{g} / \mathrm{ml} \mathrm{rHSP} 27$ combined with PAb almost completely nullifying oxLDL binding to either receptor. (Fig. 2C, 2D). The converse experiment was also carried out, using increasing concentrations of oxLDL to try to displace rHSP27 binding to either scavenger receptor. Essentially, rHSP27 combined with PAb showed $\geq 95 \% \%$ binding to SR-AI or CD-36 regardless how high the concentration oxLDL was increased (to a maximum of 164 $\mu \mathrm{g} / \mathrm{ml}$; Fig. 2E, 2F)). In contrast, rHSP27 alone was displaced from SR-AI and CD-36 at the maximum oxLDL concentration (e.g., $28 \%$ and $14 \%$ reductions in rHSP27 binding; respectively). Together, these results show that the PAb potentiated the interaction of rHSP27 with both SR-AI and CD36, thereby attenuating oxLDL binding to its cognate receptors. 
HSP27 ICAST

\section{HSP27-PAb complex attenuate uptake of oxLDL}

To assess the relative contribution of SR-AI and CD36 in oxLDL uptake we used HEK Blue ${ }^{\text {TM }}$ Null1-v cell line which is devoid of both of these receptors, and then separately transfected SRAI and CD-36 into these parental cells. First, the expression of these scavenger receptors and their abundance in HEK Blue ${ }^{\mathrm{TM}}$ cells relative to THP-1 MФ was confirmed using both Western blotting and FACS (Supplemental Fig. 3A - 3D). HEK Blue ${ }^{\mathrm{TM}}$ cells expressing SR-AI or CD36 were then treated with DiI-oxLDL and combinations of rHSP27, rC1 and PAb for $2 \mathrm{hrs}$ before performing FACS. For each experimental condition, the percentage of fluorescent cells was measured, as well as the MFI, a reflection of the amount of oxLDL that was taken up per experimental condition. HEK Blue ${ }^{\mathrm{TM}}$ Null-v cells served as negative controls and showed low (background) levels of fluorescence for PBS and all other treatments, thereby highlighting the requirement for SR-AI and CD-36 for oxLDL uptake.

For HEK Blue ${ }^{\mathrm{TM}}$ SR-AI cells the percentage of oxLDL positive cells was similar for all control conditions (PBS: 97.1\%, rC1: 97.7\%, PAb: 97.4\%), as well as treatment with rHSP27 alone (97.5\%). In contrast, treatment with the combination of [rHSP27 + PAb] resulted in $81.0 \%$ of the cells being oxLDL positive, reflecting a modest decrease. While the MFI was similar amongst the control treatments, oxLDL uptake with HSP27 IC treatment was $65.2 \%$ lower than with rHSP27 treatment (2,390 vs. 6,869 a.u.) (Fig. 3A).

For the HEK Blue ${ }^{\mathrm{TM}}$ CD-36 cells, the percentage of cells with oxLDL uptake for the control treatments were similar (e.g., PBS 92.2\%, rC1 91.8\%, PAb 92.9\%). However, the percentage of cells with oxLDL uptake for the [rHSP27 + PAb] treatment group was only $73.3 \%$ compared to 
HSP27 ICAST

the cells treated with rHSP27 alone (93.0\%). For the cells treated with [rHSP27 + PAb] the MFI was $43.3 \%$ lower than those treated with rHSP27 alone (4,815 vs. 2,731 a.u., Fig. 3A).

Next we addressed the same question of the effect of the HSP27 IC on oxLDL uptake in THP-1 M $\Phi$ using both FACS and a plate reader assay. DiI-oxLDL uptake was reduced in the presence of HSP27 IC by both techniques:

a) For the FACS studies, the percentage of cells fluorescent for DiI-oxLDL was similar amongst the controls: PBS (92.7\%), rC1 (93.3\%) and PAb (89.95), but dropped to $75.8 \%$ with [rHSP27+PAb] treatment (Fig. 3B). With regards to the MFI signal that reflects the amount of DiI-oxLDL uptake for each experimental condition, the rHSP27 (alone) treatment group $(4,972)$ was indistinguishable from the PBS control (4,996 a.u.). However, MФ treated with [rHSP27 + PAb] had a 31\% lower MFI signal (3,440 a.u) compared to rHSP27 alone.

b) A plate reader assay showed a similar 38\% reduction of DiI-oxLDL uptake with the rHSP27 IC compared to rHSP27 alone ( $\mathrm{p}=0.003)$, and no changes with $\mathrm{rC} 1, \mathrm{rHSP} 27, \mathrm{PAb}$ alone or rC1 and PAb (Fig. 3C).

\section{rHSP27 Internalization}

FACS studies were also used to examine the uptake of rHSP27 when the PAb is added. The percentage of cells that were fluorescent for FITC-labeled rHSP27 was comparable amongst the controls: PBS (1.2\%) and PAb (1.5\%); while, the uptake of $\mathrm{rC} 1$ alone (19.7\%) and $\mathrm{rC} 1+\mathrm{PAb}$ (33.4\%) were higher. Nonetheless, rHSP27 alone (82.9\%) and [rHSP27+PAb] (80.0\%) were much higher, and similar - thereby suggesting that approximately the same percentage of cells showed uptake of rHSP27 vs. the rHSP27 IC. However, on reviewing the amount of FITC- 
HSP27 ICAST

labelled rHSP27 taken up (i.e., the MFI), treatment with the rHSP27 IC resulted in $56.1 \%$ greater uptake relative to rHSP27 alone (9,380 vs. 6,009), with all controls being much lower (Fig. 4A). A rHSP27 uptake assay using a plate reader to quantify the FITC signal in M $\Phi$ showed virtually no uptake at $4 \mathrm{hrs}$, but by $16 \mathrm{hrs}$ the uptake was $135 \%$ greater with the HSP27 IC compared too rHSP27 alone $(\mathrm{p}<0.001)$, with negligible uptake of $\mathrm{rC} 1$ with or without of the PAb (Fig. 4B, 4C). Like the FACS result, there did not seem to be an overwhelming increase in the number of FITC positive MФ, rather the brightness signal in the positive cells appeared stronger, thereby implying increased uptake in certain but not all cells.

\section{Discussion}

Investigations by several laboratories, including our own, highlight the point that HSP27 arterial expression and blood levels are higher in health compared to cardiovascular disease (3-7). As well, we now know that AAb levels are also higher in health but have yet to fully understand their role (11). Recently, we generated data to suggest that [HSP27 + PAb] can act from outside the cell to produce signals that result in reduced inflammation and blood cholesterol levels due to increased expression of the low density lipoprotein (LDL) receptor that requires TLR4 and activation of the NF- $\kappa \mathrm{B}$ pathway (11). A second major series of observation from our group is that interventions that increase HSP27 levels are associated with reduced plaque content of both MФ and cholesterol clefts $(8,10)$. We postulate that this effect is not solely due to reduced plasma cholesterol levels, as previously we showed that HSP27 (alone) can bind SR-AI to reduce uptake of modified LDL particles in vitro (19), we have not taken into account the potential role of AAbs. Similarly, a number of important studies from eminent groups in the heat shock protein (HSP) field provide important insights into how various HSPs, including HSP27, interact at the 
HSP27 ICAST

cell membrane (20-23), yet none consider the potential role of antibodies to the respective HSPs. Intuitively, one might surmise that these anti-HSP27 antibodies are detrimental to the biology of HSP27, essentially covering up the protein and barring it for performing its beneficial extracellular functions. Hence, the goal of this study was to examine the effect of combining a

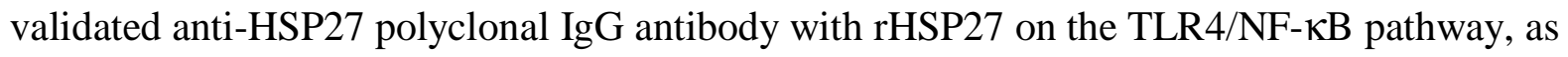
well MФ scavenger receptor biology. Three important clusters of observations arose from these

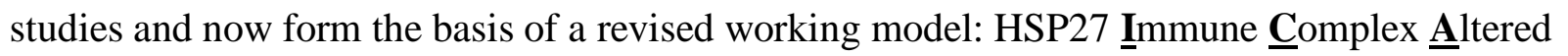

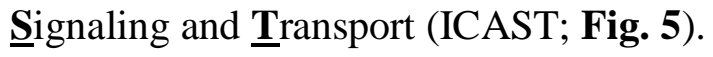

First, the HSP27 IC is superior to HSP27 alone in binding the M $\Phi$ membrane (Fig. 1). TLR4 is important in the interaction of the HSP27 IC with the MФ membrane, and is definitely required for the activation of NF- $\kappa$ B. The transcription factor NF- $\kappa$ B is a key regulator of inflammation, immune responses, cell survival, and cell proliferation (24). Upon activation, NF- $\kappa \mathrm{B}$ can mediate the induction of more than 160 genes, many of which have documented roles in both atherogenesis and athero-protection $(12,25)$. Activated NF- $\kappa \mathrm{B}$ has been detected in endothelial cells, smooth muscle cells, and MФ in atherosclerotic plaques, which may be involved in either the development or protection of atherosclerosis $(26,27)$. Interestingly, we note in this study a decrease in LPS-mediated NF- $\kappa \mathrm{B}$ activation when the HSP27 IC is present. Moreover, treatment of MФ with the HSP27 IC markedly reverses the balance of the inflammatory cytokines secreted in response to LPS treatment (e.g., a $75 \%$ reduction in IL-1 $\beta$ and a $167 \%$ increase in IL-10). So there appears to be a yin and yang, whereby activation of $\mathrm{NF}-\kappa \mathrm{B}$ can be detrimental if it results

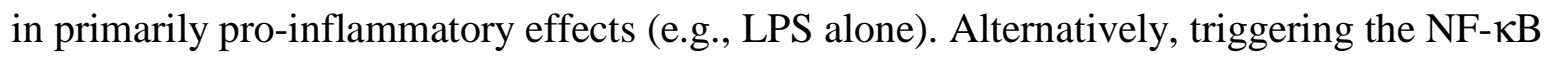
pathway with HSP27 ICs can suppress (or out-compete) inflammatory mediators such as LPS for 
HSP27 ICAST

TLR4, and/or enact athero-protective effects, such as the upregulation of LDLR transcription (11). Certainly, this dualism in HSP27 IC signaling is becoming increasing interesting and forms the basis of our future studies.

Second, the HSP27 IC binds both SR-AI and CD-36, and can displace oxLDL binding with these scavenger receptors, resulting in less oxLDL uptake in MФ (Fig. 2, 3). Out of all of the handful of scavenger receptors that have been identified, SR-AI and CD36 are the two main receptors interacting with and then ingesting oxLDL.(28) oxLDL plays a key pro-atherogenic role in the arterial wall. Various known vascular risk factors are associated with increased oxidative stress that transforms native LDL to oxLDL and the formation of foam cells that populate atherosclerotic plaques. Previously we showed that the uptake of oxLDL by THP-1 M $\Phi$ is hampered by treatment with high dose $\operatorname{HSP} 27$ alone $(250 \mu \mathrm{g} / \mathrm{ml})(9,13)$, which actually downregulates SR-AI expression (13). In the current studies we note that at more physiological HSP27 concentrations $(1 \mu \mathrm{g} / \mathrm{ml})$ there is no inhibition of MФ oxLDL uptake, except when rHSP27 combines with the PAb. Indeed, compared to HSP27 alone, the HSP27 IC has a stronger affinity for both SR-AI and CD36, thereby out-competing oxLDL and reducing its endocytosis through these receptors.

Third, combining the PAb with rHSP27 results in enhanced cellular uptake and internalization of rHSP27 in MФ. Although we recently noted how HSP25 vaccination in mice augments the expression of LDLR by increasing the activity of its promoter (11), we struggled with trying to understand how HSP27 could somehow traverse the cell membrane to alter transcription. The current data provide initial insights regarding the internalization process, highlighting how it is 
HSP27 ICAST

facilitated by the presence of the anti-HSP27 antibody. Certainly, more study is required to dissect the internal signaling pathways before we can better understand the effects of HSP27 on (say) LDLR transcription, and if there are direct or indirect effects on the LDLR promoter.

In summary, the IC formed between HSP27 and its autoantibody, potentiates the interaction with the MФ cell membrane, a process that involves TLR4 and the scavenger receptors SR-AI and CD-36. The activation of the NF-אB pathway is more potent with the HSP27 IC vs. HSP27 alone, yet modest compared to LPS alone. Similarly, the HSP27 IC is superior to HSP27 alone in competing with SR-AI and CD-36 for the uptake of oxLDL - which may be very important for not only plaque $\mathrm{M} \Phi$, but also the in the development of non-alcoholic fatty liver disease, an important metabolic issue that predisposes to liver fibrosis and coronary artery disease. To date, this is the first report of the HSP27 IC acting as an innate antagonist of inflammatory signaling and MФ foam cell formation. Taken together, these studies provide further stimulus to develop either active or passive HSP27 immunization strategies that boost AAb levels for the prevention and/or treatment of atherosclerosis and other inflammatory diseases.

\section{Acknowledgments}

We are indebted to the Libin Cardiovascular Institute of Alberta and its community partners for supporting the O'Brien Vascular Biology Laboratory and associated infrastructural research entities. We appreciate the support of many collaborators at the University of Calgary including: Paul Kubes PhD for TLR4 ${ }^{-/-}$mice, Dr. Elmar Prenner's laboratory in the Department of Biological Sciences where the ITC studies were performed and Yiping Liu, MD, PhD in the Flow Cytometry core facility at the Cumming School of Medicine. 


\section{HSP27 ICAST}

\section{References:}

1. Schwartz, S. M., deBlois, D., and O'Brien, E. R. (1995) The Intima: Soil for atherosclerosis and restenosis. Circulation research 77, 445-465

2. Batulan, Z., Pulakazhi Venu, V. K., Li, Y., Koumbadinga, G., Alvarez-Olmedo, D. G., Shi, C., and O'Brien, E. R. (2016) Extracellular Release and Signaling by Heat Shock Protein 27: Role in Modifying Vascular Inflammation. Front Immunol 7, 285

3. Miller, H., Poon, S., Hibbert, B., Rayner, K., Chen, Y. X., and O'Brien, E. R. (2005) Modulation of estrogen signaling by the novel interaction of heat shock protein 27, a biomarker for atherosclerosis, and estrogen receptor beta. Arteriosclerosis Thrombosis and Vascular Biology 25, E10-E14

4. Martin-Ventura, J. L., Duran, M. C., Blanco-Colio, L. M., Meilhac, O., Leclercq, A., Michel, J. B., Jensen, O. N., Hernandez-Merida, S., Tunon, J., Vivanco, F., and Egido, J. (2004) Identification by a differential proteomic approach of heat shock protein 27 as a potential marker of atherosclerosis. Circulation 110, 2216-2219

5. Park, H. K., Park, E. C., Bae, S. W., Park, M. Y., Kim, S. W., Yoo, H. S., Tudev, M., Ko, Y. H., Choi, Y. H., Kim, S., Kim, D. I., Kim, Y. W., Lee, B. B., Yoon, J. B., and Park, J. E. (2006) Expression of heat shock protein 27 in human atherosclerotic plaques and increased plasma level of heat shock protein 27 in patients with acute coronary syndrome. Circulation 114, 886-893

6. Lepedda, A. J., Cigliano, A., Cherchi, G. M., Spirito, R., Maggioni, M., Carta, F., Turrini, F., Edelstein, C., Scanu, A. M., and Formato, M. (2009) A proteomic approach to differentiate histologically classified stable and unstable plaques from human carotid arteries. Atherosclerosis 203, 112-118 
7. Liang, W., Ward, L. J., Karlsson, H., Ljunggren, S. A., Li, W., Lindahl, M., and Yuan, X. M. (2016) Distinctive proteomic profiles among different regions of human carotid plaques in men and women. Sci Rep 6, 26231

8. Seibert, T. A., Hibbert, B., Chen, Y. X., Rayner, K., Simard, T., Hu, T., Cuerrier, C. M., Zhao, X., de Belleroche, J., Chow, B. J., Hawken, S., Wilson, K. R., and O'Brien, E. R. (2013) Serum heat shock protein 27 levels represent a potential therapeutic target for atherosclerosis: observations from a human cohort and treatment of female mice. $J \mathrm{Am}$ Coll Cardiol 62, 1446-1454

9. Rayner, K., Chen, Y. X., McNulty, M., Simard, T., Zhao, X., Wells, D. J., de Belleroche, J., and O'Brien, E. R. (2008) Extracellular release of the atheroprotective heat shock protein 27 is mediated by estrogen and competitively inhibits acLDL binding to scavenger receptor-A. Circulation research 103, 133-141

10. Cuerrier, C. M., Chen, Y. X., Tremblay, D., Rayner, K., McNulty, M., Zhao, X., Kennedy, C. R., de, B. J., Pelling, A. E., and O'Brien, E. R. (2013) Chronic overexpression of heat shock protein 27 attenuates atherogenesis and enhances plaque remodeling: a combined histological and mechanical assessment of aortic lesions. PLoS ONE 8, e55867

11. Chen, Y.-X., Shi, C., Deng, J., Diao, C., Maarouf, N., Rosin, M., Shrivastava, V., Hu, A., Bharadwa, S., Adijiang, A., Ulke-Lemee, A., Gwilym, B. L., Hellmich, A., Malozzi, C., Batulan, Z., Dean, J. L. E., Ramirez, F. D., Liu, J., Gerthoffer, W. T., and O'Brien, E. R. (2020) Heat Shock Protein 27 Immune Complex Upregulates LDLR Expression Thereby Reducing Plasma Cholesterol and Atherogenesis. bioRxiv, 2020.2005.2021.102350 
HSP27 ICAST

12. Salari, S., Seibert, T., Chen, Y. X., Hu, T., Shi, C., Zhao, X., Cuerrier, C. M., Raizman, J. E., and O'Brien, E. R. (2013) Extracellular HSP27 acts as a signaling molecule to activate NF-kappaB in macrophages. Cell Stress Chaperones 18, 53-63

13. Raizman, J. E., Chen, Y. X., Seibert, T., Hibbert, B., Cuerrier, C. M., Salari, S., Zhao, X., Hu, T., Shi, C., Ma, X., Simard, T., Caravaggio, J., Rayner, K., Bowdish, D., Moore, K., and O'Brien, E. R. (2013) Heat shock protein-27 attenuates foam cell formation and atherogenesis by down-regulating scavenger receptor-A expression via NF-kappaB signaling. Biochimica et biophysica acta 1831, 1721-1728

14. Leavitt, S., and Freire, E. (2001) Direct Measurement of Protein Binding Energetics by Isothermal Titration Calorimetry. Current Opinion in Structural Biology 11, 560-566

15. Ladbury, J. E., and Chowdhry, B. Z. (1996) Sensing the Heat: the application of isothermal titration calorimetry to thermodynamic studies of biomolecular interactions. Chemistry \& Biology 3, 791-801

16. Feig, A. L. (2007) Applications of Isothermal Titration Calorimetry in RNA Biochemistry and Biophysics. Biopolymers 87, 293-301

17. Gaisford, S. (2005) Stability Assessment of Pharmaceuticals and Biopharmaceuticals by Isothermal Calorimetry. Current Pharmaceutical Biotechnology 6, 181-191

18. Pulakazhi Venu, V. K., Adijiang, A., Seibert, T., Chen, Y. X., Shi, C., Batulan, Z., and O'Brien, E. R. (2017) Heat shock protein 27-derived atheroprotection involves reverse cholesterol transport that is dependent on GM-CSF to maintain ABCA1 and ABCG1 expression in ApoE(-/-) mice. FASEB J 31, 2364-2379

19. Rayner, K., Sun, J., Chen, Y. X., McNulty, M., Simard, T., Zhao, X., Wells, D. J., de Belleroche, J., and O'Brien, E. R. (2009) Heat shock protein 27 protects against 


\section{HSP27 ICAST}

atherogenesis via an estrogen-dependent mechanism: role of selective estrogen receptor beta modulation. Arteriosclerosis, thrombosis, and vascular biology 29, 1751-1756

20. Schmitt, E., Gehrmann, M., Brunet, M., Multhoff, G., and Garrido, C. (2007)

Intracellular and extracellular functions of heat shock proteins: repercussions in cancer therapy. J Leukoc Biol 81, 15-27

21. Vega, V. L., Rodriguez-Silva, M., Frey, T., Gehrmann, M., Diaz, J. C., Steinem, C., Multhoff, G., Arispe, N., and De, M. A. (2008) Hsp70 translocates into the plasma membrane after stress and is released into the extracellular environment in a membraneassociated form that activates macrophages. J Immunol 180, 4299-4307

22. Thuringer, D., Jego, G., Wettstein, G., Terrier, O., Cronier, L., Yousfi, N., Hebrard, S., Bouchot, A., Hazoume, A., Joly, A. L., Gleave, M., Rosa-Calatrava, M., Solary, E., and Garrido, C. (2013) Extracellular HSP27 mediates angiogenesis through Toll-like receptor 3. FASEB J 27, 4169-4183

23. Shevtsov, M., Balogi, Z., Khachatryan, W., Gao, H., Vígh, L., and Multhoff, G. (2020) Membrane-Associated Heat Shock Proteins in Oncology: From Basic Research to New Theranostic Targets. Cells 9

24. Kanters, E., Pasparakis, M., Gijbels, M. J., Vergouwe, M. N., Partouns-Hendriks, I., Fijneman, R. J., Clausen, B. E., Forster, I., Kockx, M. M., Rajewsky, K., Kraal, G., Hofker, M. H., and de Winther, M. P. (2003) Inhibition of NF-kappaB activation in macrophages increases atherosclerosis in LDL receptor-deficient mice. J Clin Invest 112,

\section{6-1185}

25. Collins, T., and Cybulsky, M. I. (2001) NF-kappaB: pivotal mediator or innocent bystander in atherogenesis? J Clin.Invest 107, 255-264 
HSP27 ICAST

26. Brand, K., Page, S., Rogler, G., Bartsch, A., Brandl, R., Knuechel, R., Page, M.,

Kaltschmidt, C., Baeuerle, P. A., and Neumeier, D. (1996) Activated Transcription Factor

Nuclear Factor-Kappa B Is Present in the Atherosclerotic Lesion. Journal of Clinical

Investigation 97, 1715-1722

27. Hajra, L., Evans, A. I., Chen, M., Hyduk, S. J., Collins, T., and Cybulsky, M. I. (2000)

The NF-kappa B signal transduction pathway in aortic endothelial cells is primed for activation in regions predisposed to atherosclerotic lesion formation. Proc Natl Acad Sci

U S A 97, 9052-9057

28. Steinbrecher, U. P. (1999) Receptors for oxidized low density lipoprotein. Biochimica et biophysica acta 1436, 279-298 
Fig. 1

A

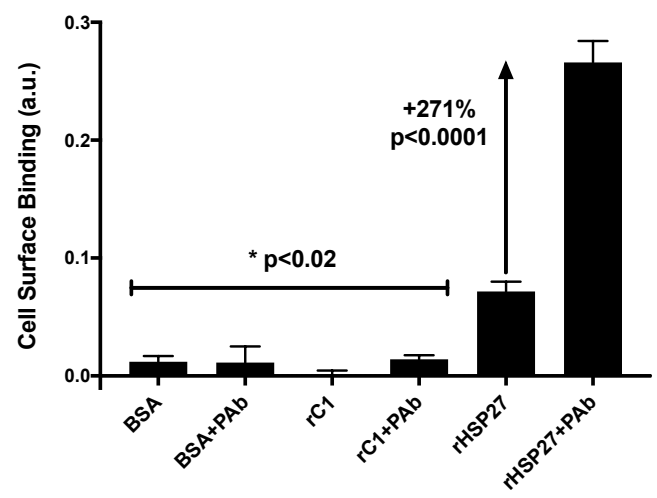

C

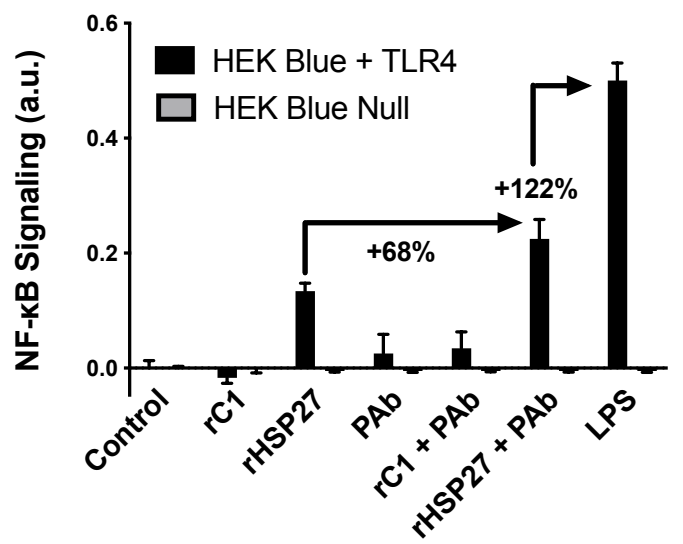

E

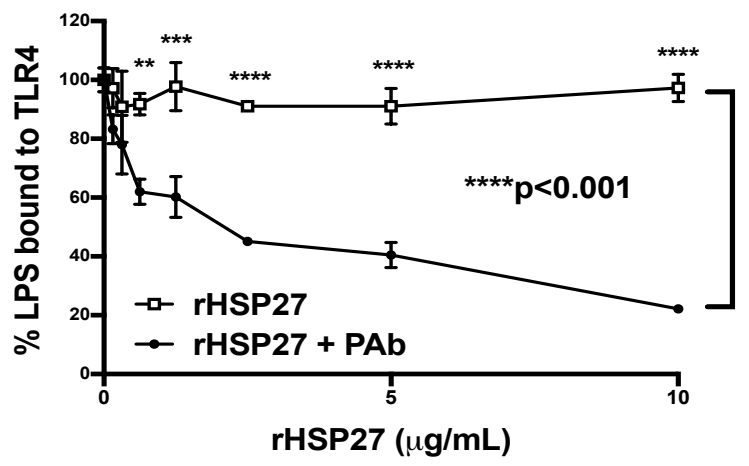

B

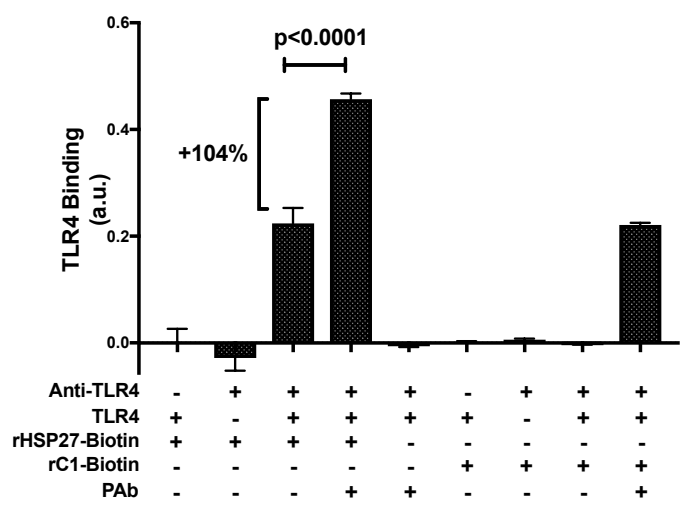

D

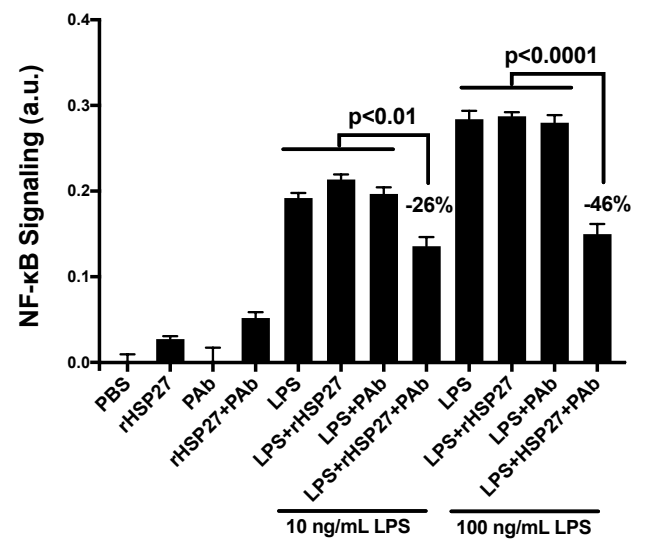

F

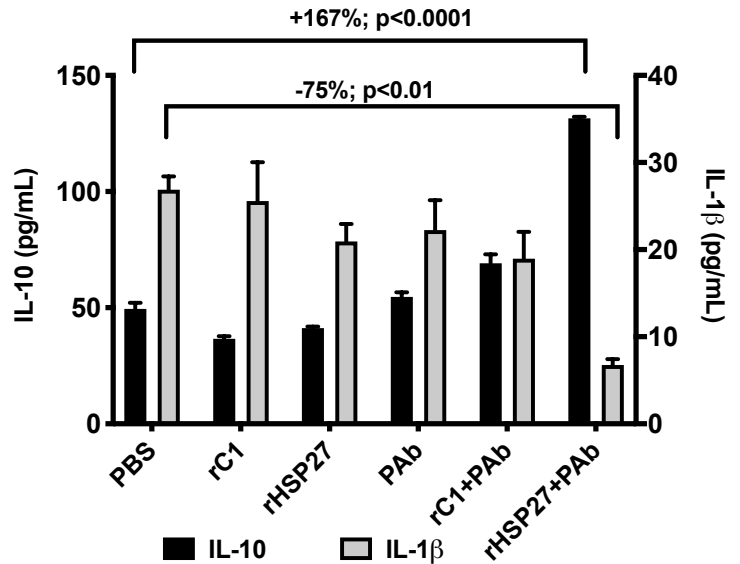




\section{Fig. 1. Hsp27 autoantibodies potentiate the anti-inflammatory effect of Hsp27}

A) Cell surface binding assay using THP-1 MФ, showing that PAbs promotes a $271 \%$ increase in rHSP27 binding to the cell surface $(\mathrm{p}<0.0001)$.

B) In vitro binding assay using THP-1 MФ cell lysates, showing that the presence of PAB strengthens rHSP27 binding to TLR4 by 104\% $(\mathrm{p}<0.0001)$.

C) NF-kB SEAP reporter gene assay of THP1-XBlue ${ }^{\mathrm{TM}}$ MФ monocytes treated for $24 \mathrm{hr}$ with different combinations of $\mathrm{rHSP} 27(1 \mu \mathrm{g} / \mathrm{ml}), \mathrm{rC} 1(1 \mu \mathrm{g} / \mathrm{ml})$, and PAb $(5 \mu \mathrm{g} / \mathrm{ml})$. The addition of the PAb to rHSP27 increased NF-kB signaling by $68 \%$ compared to HSP27 alone, but paled in comparison to LPS. Cells devoid of TLR4 showed only background NF- $\kappa$ B signals in response to all treatments.

D) NF- $\kappa$ B reporter assay using THP1 XBlue ${ }^{\mathrm{TM}} \mathrm{M} \Phi$ shows that $[\mathrm{rHSP} 27+\mathrm{PAb}$ increased NFКB signaling compared to rHSP27 alone. More importantly, the HSP27 IC attenuated LPSmediated activation of NF- $\kappa$ B by $26 \%$ and $46 \%$ for LPS concentrations of 10 and $100 \mathrm{ng} / \mathrm{ml}$ $(\mathrm{p}<0.01$ and $<0.0001$; respectively), thereby highlighting a competition between LPS and the HSP27 IC for TLR4.

E) The HSP27 IC competitively inhibits the binding of biotinylated LPS to TLR4 by as much as $77 \%$ compared to HSP27 alone $(\mathrm{p}<0.001)$.

F) In the culture media of THP-1 MФ treated with LPS, cotreatment with [rHSP27 + PAb] decreased the concentration of IL- $1 \beta$ by $75 \%(\mathrm{p}<0.01$; left axis $)$ and increased IL-10 by $167 \%$ $(\mathrm{p}<0.0001$; right axis). 
Fig. 2

A

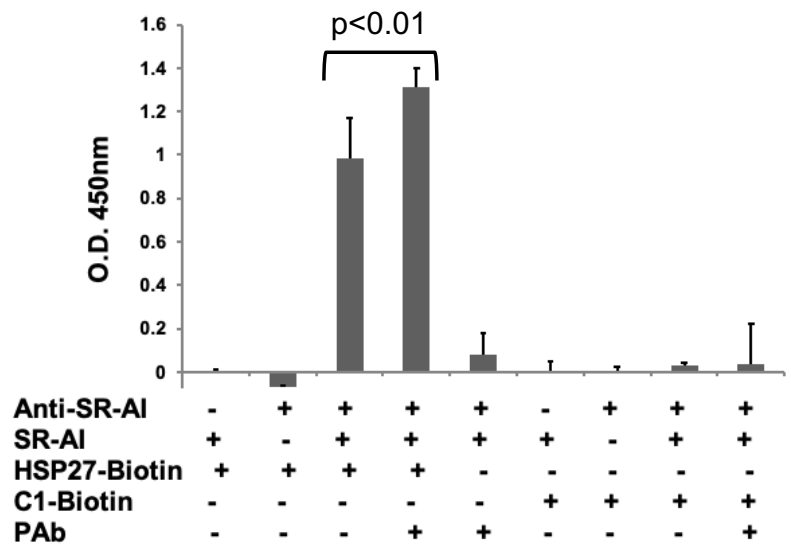

C

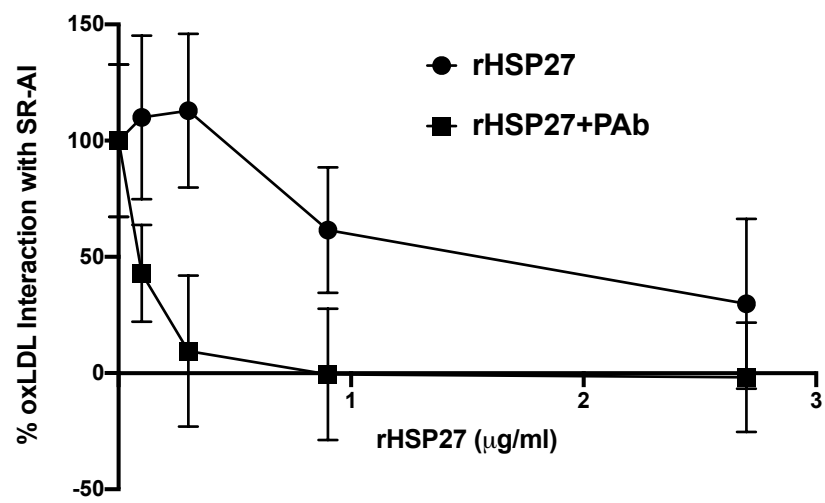

E

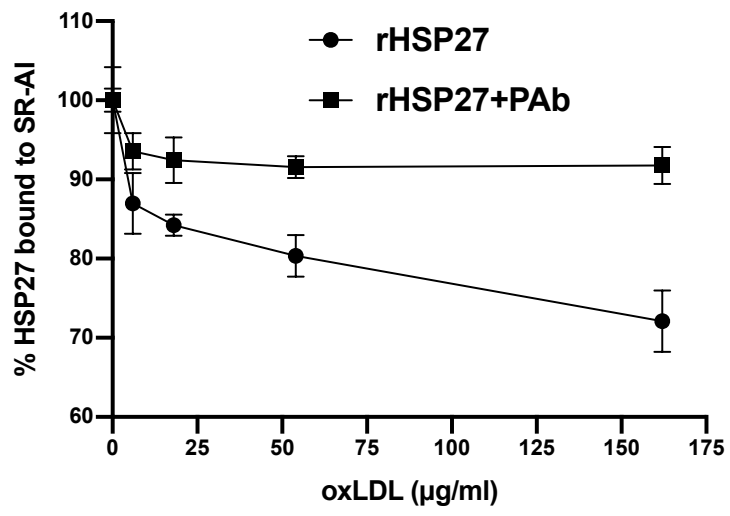

B

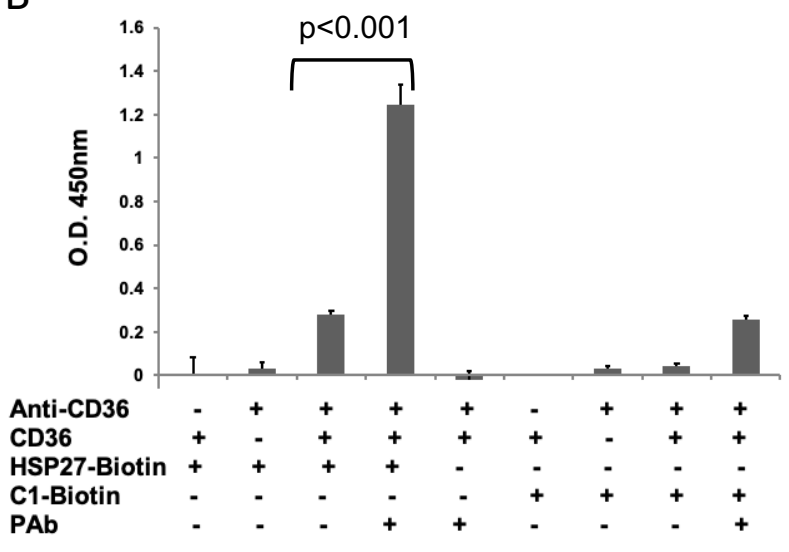

D

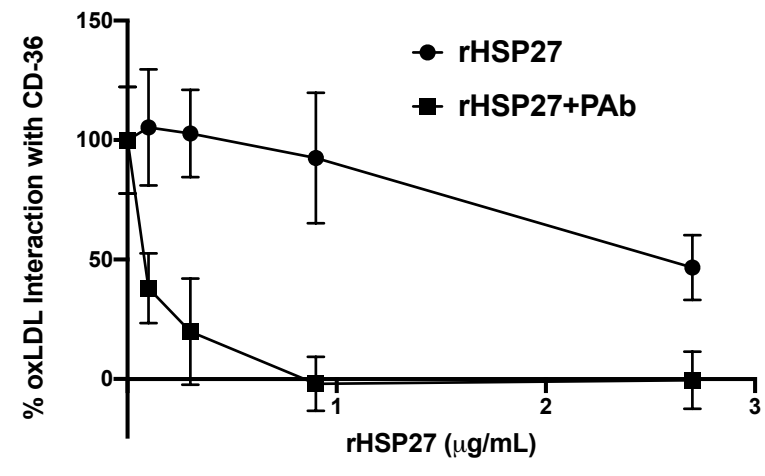

F

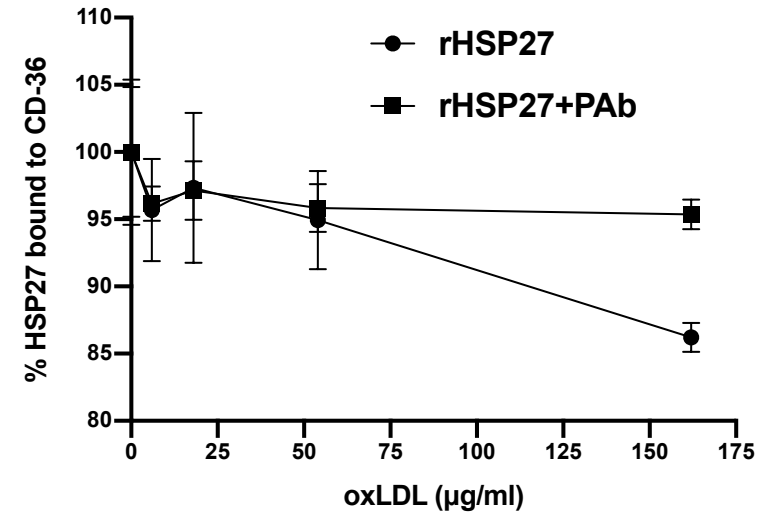


Fig. 2. HSP27 IC competes with oxLDL to bind scavenger receptors SR-AI and CD36

A-B) In vitro binding assay using THP-1 MФ cell lysates to show that the presence of PAb strengthened the binding of rHSP27 to either SR-AI or CD36.

C-D) The interaction between oxLDL and SR-AI or CD36 is efficiently blocked by the HSP27

IC, but not HSP27 alone.

E-F) Unlike the HSP27 (alone), the interaction between rHSP27 IC and either SR-AI or CD36 is effectively unchanged despite increasing the concentration of oxLDL. 
Fig. 3

A

HEK Blue SR-AI
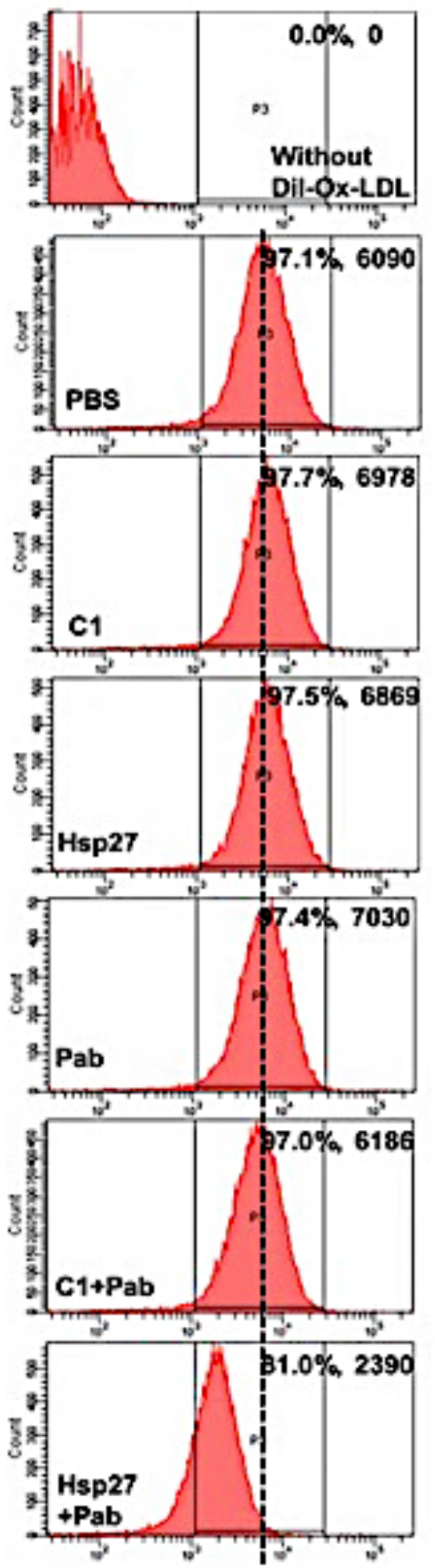

HEK Blue CD36
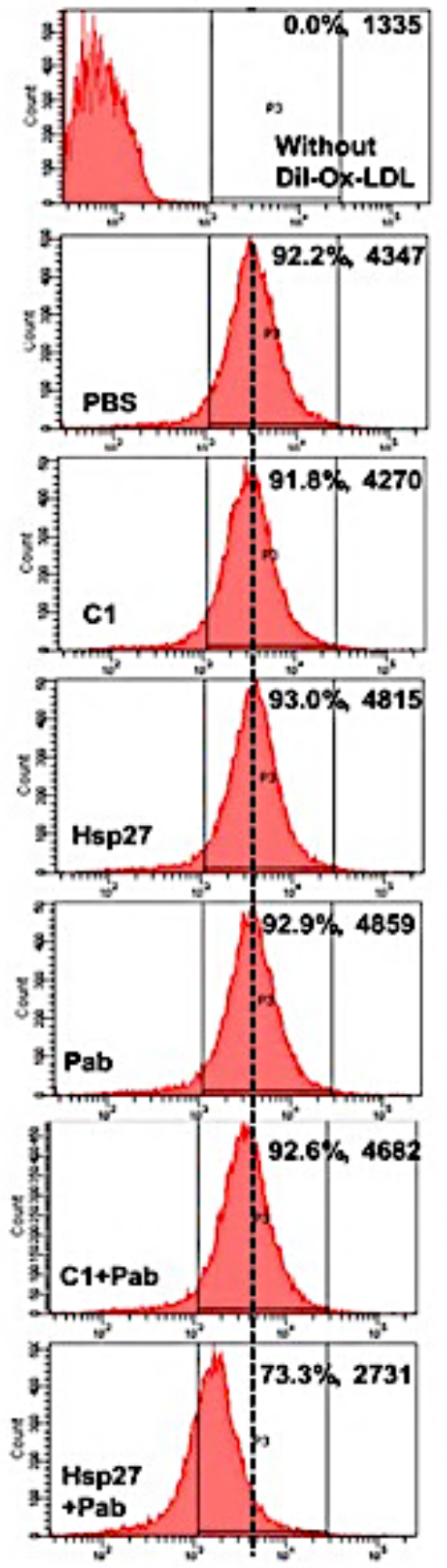

HEK Blue Null
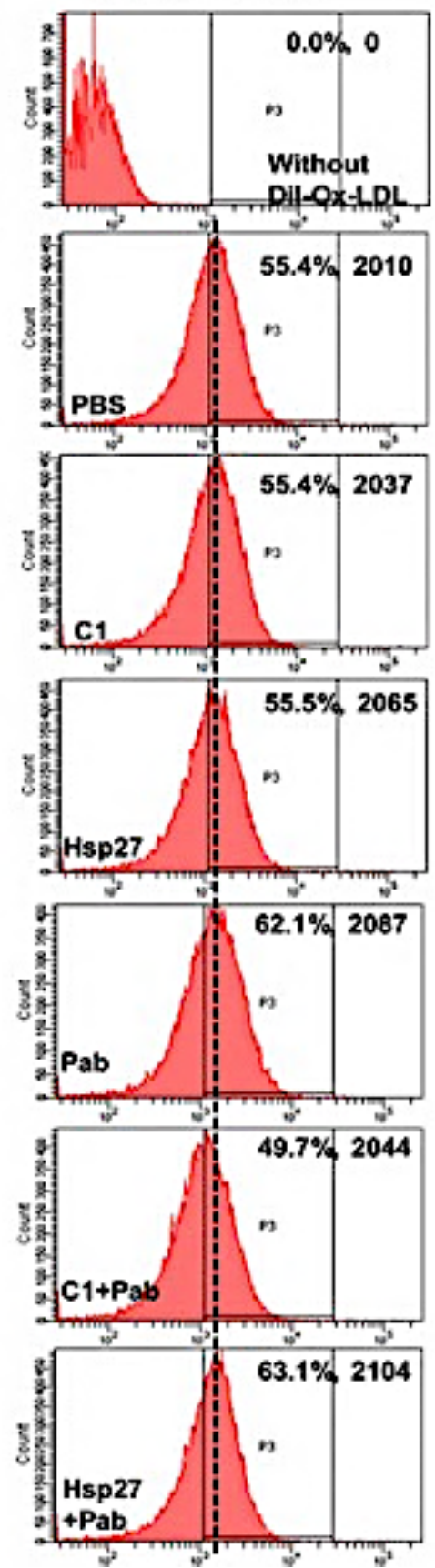
Fig. 3 (continued)

B
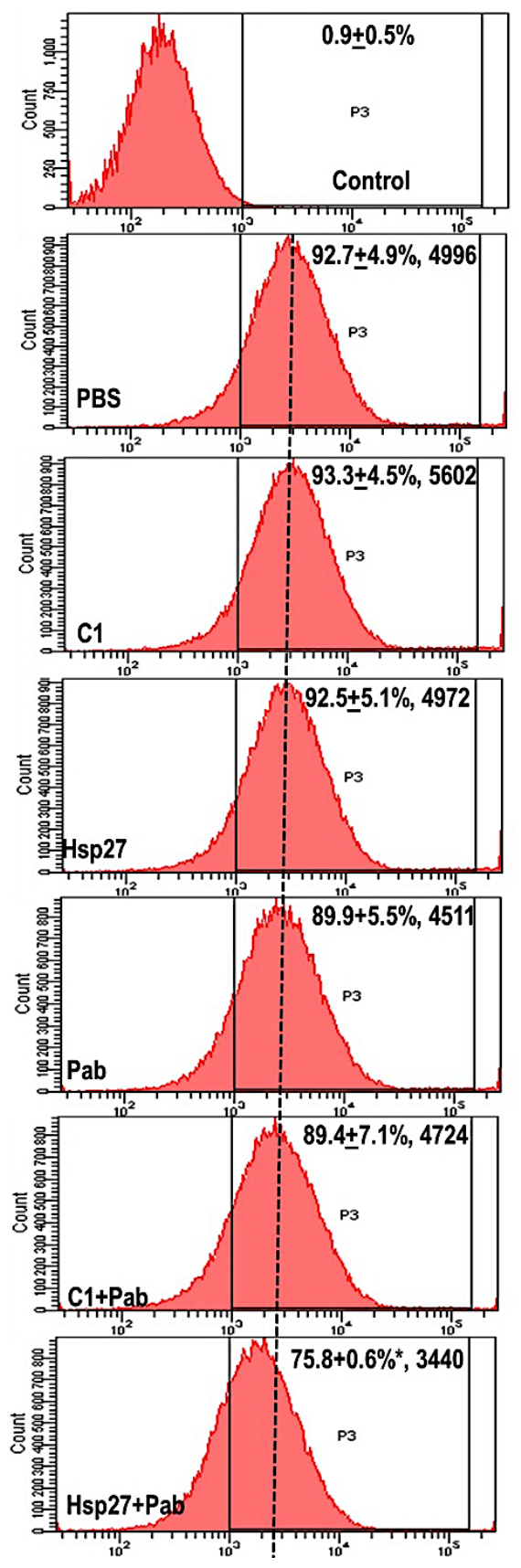

C

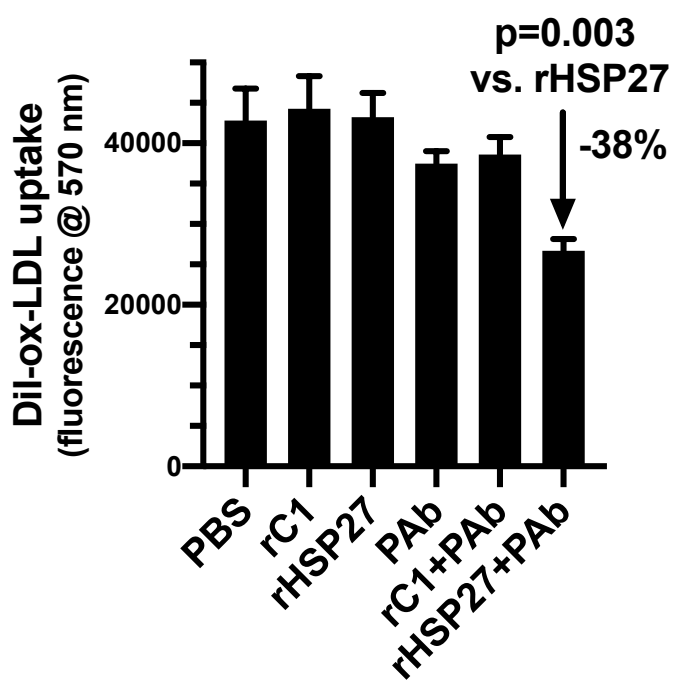




\section{Fig. 3. oxLDL uptake by scavenger receptors is inhibited by the HSP27 IC}

A) Flow cytometry study of DiI-oxLDL uptake in HEK Blue ${ }^{\mathrm{TM}}$ cells expressing SR-AI (left), CD36 (middle) or Null (right). Cells were treated with combinations of rHSP27, rC1 and $\mathrm{PAb}$, and the following parameters were recorded: i) percentage of cells positive for DiIoxLDL fluorescence, and ii) The mean fluorescence intensity for DiI-oxLDL uptake per treatment group. Compared to PBS control, the presence of HSP27 IC reduced DiI-oxLDL uptake by $61 \%$ and $37 \%$ from SR-AI and CD36 expressing cells, respectively, whereas the other control treatments had negligible effects.

B) THP-1 MФ study similar to A), showing that compared to PBS control, Dil-oxLDL uptake is reduced from $92.7 \%$ to $75.8 \%$ with the HSP27 IC. Similarly, the MFI signal for the HSP27 IC was $31 \%$ lower than that of rHSP27 alone.

C) Plate reader assay with THP-1 MФ showing a 38\% reduction in DiI-oxLDL uptake with the HSP27 IC compared to rHSP27 alone $(p=0.003)$. 
Fig. 4

A
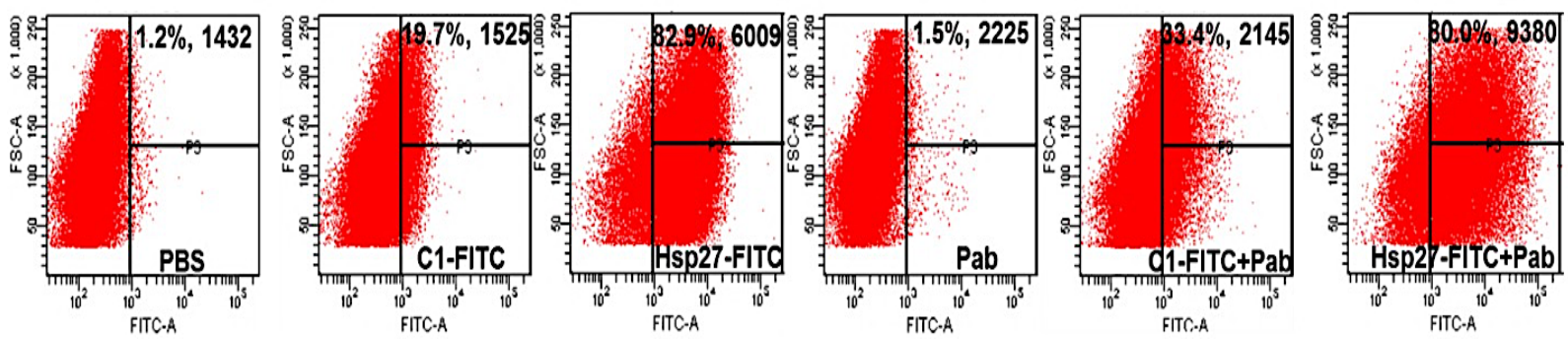

B

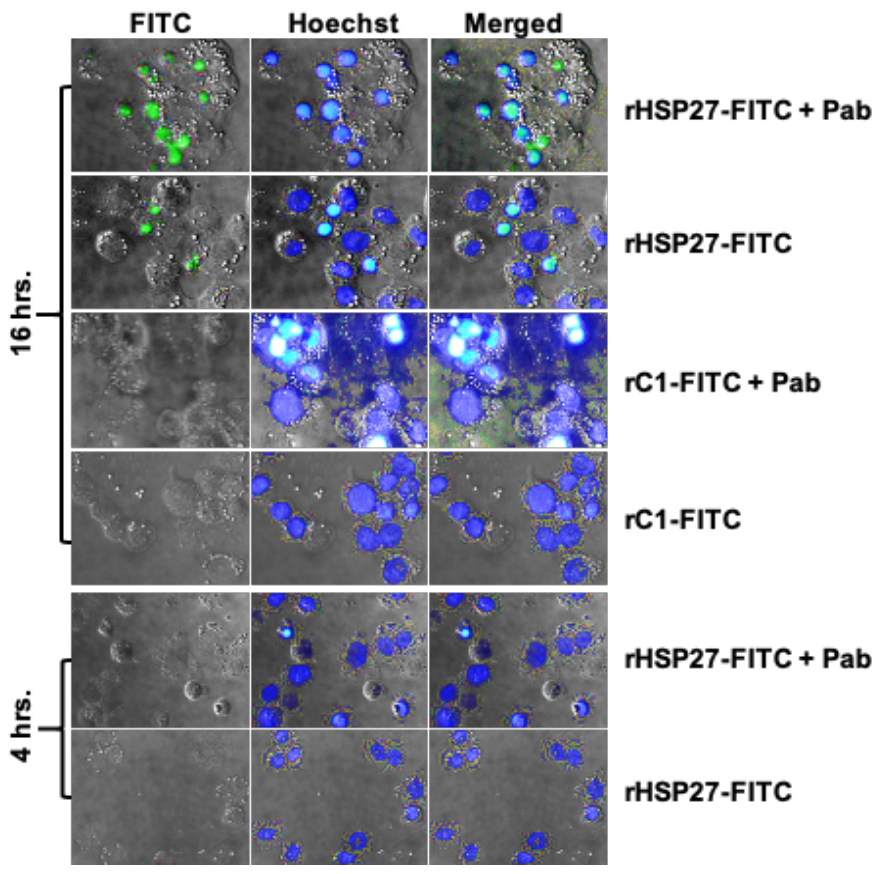

C

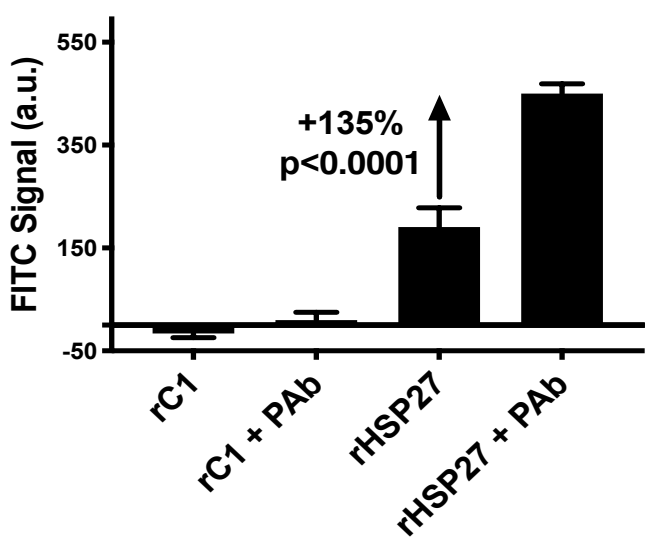


bioRxiv preprint doi: https://doi.org/10.1101/2020.05.31.126581; this version posted June 1, 2020. The copyright holder for this preprint (which

was not certified by peer review) is the author/funder, who has granted bioRxiv a license to display the preprint in perpetuity. It is made available under aCC-BY-NC-ND 4.0 International license.

HSP27 ICAST

\section{Figure 4. PAb enhances rHSP27 endocytosis in THP-1 МФ}

A) Using flow cytometry (A) the uptake of FITC-labelled rHSP27 is enhanced by with the addition of the PAb.

B) Confocal microscopy demonstrating enhanced uptake of FITC-labelled rHSP27 in THP-

$1 \mathrm{M} \Phi$ at 16 but not 4 hrs (phase contrast and fluorescent microscopy; $\times 200)$.

C) FITC-rHSP27 uptake is markedly increased when the PAb is combined with rHSP27. 
Fig. 5

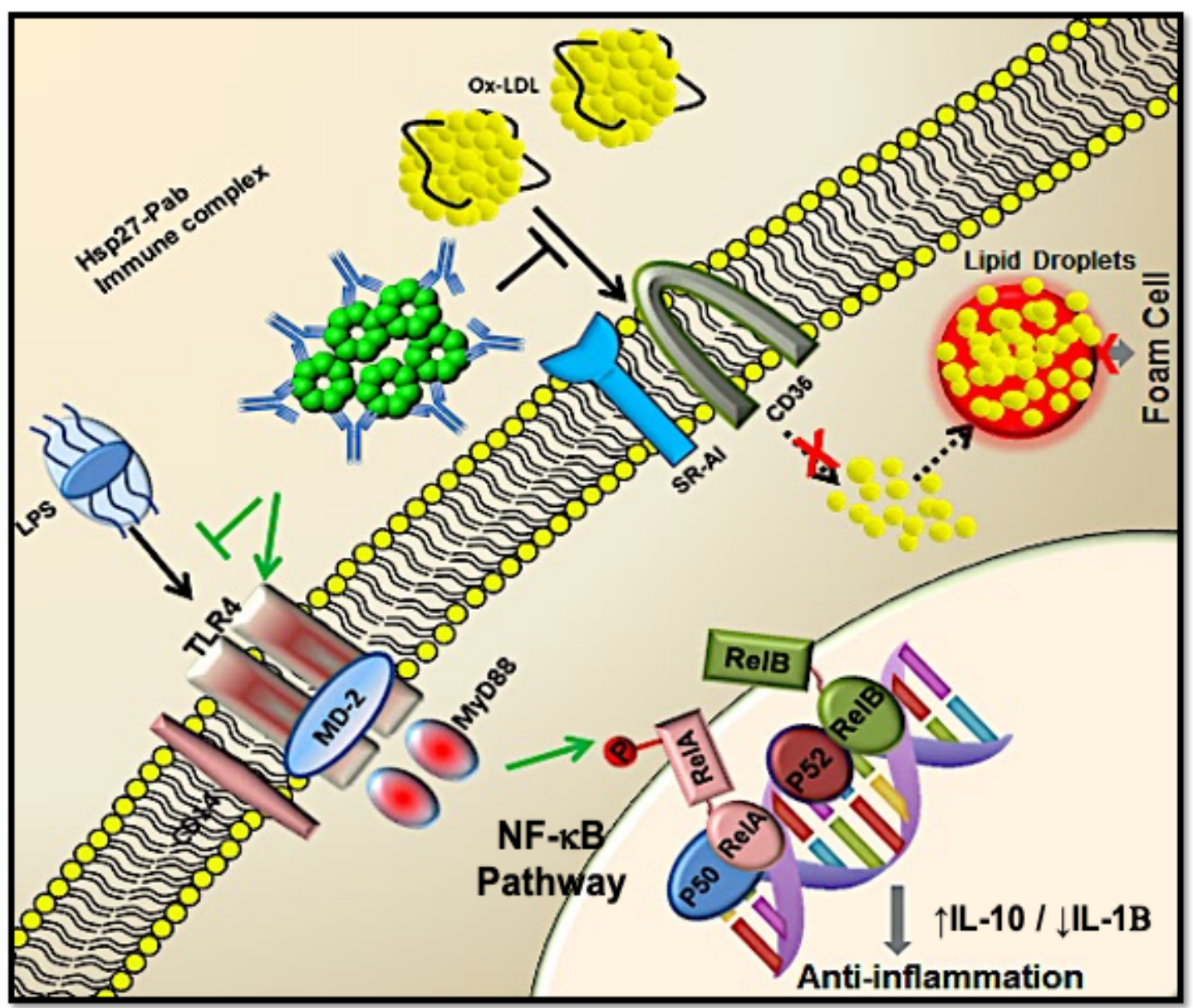


HSP27 ICAST

\section{Fig. 5 ICAST Schematic}

Outline of the working hypothesis as to how the HSP27 IC reduces MФ inflammatory signaling, blocks oxLDL uptake and can undergo internalization. Binding of HSP27 to the cell membrane is facilitated by the addition of the AAb. The HSP27 IC interacts with TLR4 to activate the NF$\kappa \mathrm{B}$ pathway, competitively displacing the interaction of LPS with this receptor. Activation of $\mathrm{NF}-\kappa \mathrm{B}$ by this external pathway effects an anti-inflammatory milieu with levels of secreted IL10 increased and IL-1 $\beta$ decreased. As well, the HSP27 IC competes with oxLDL for binding to scavenger receptors SR-AI and CD-36, thereby reducing oxLDL internalization and foam cell formation. Finally, the presence of the PAb enhances the internalization of HSP27 (not shown) via mechanisms that are currently under study. 